\title{
Reversible Addition-Fragmentation Chain Transfer [RAFT] Polymerization of Poly[ethylmethacrylate] with Pendant Carbazole Groups
}

\author{
Shienna Marie Pontillas ${ }^{1}$, Florentino C. Sumera ${ }^{2^{*}}$ and Rigoberto C. Advincula ${ }^{3}$ \\ ${ }^{1}$ Department of Science and Technology, Bicutan, Taguig City \\ ${ }^{2}$ Environmental Health Laboratory Services Cooperative, \#50 Holy Spirit Drive, Don Antonio Heights, \\ Quezon City \\ ${ }^{3}$ Case Western Reserve University, 2100, Adelbert Road, Kent Hale Smith Bldg., Cleveland, Ohio, 44106, USA
}

\begin{abstract}
Carbazole containing polymers have captured the interest of researchers for use in optoelectronics. For an important material to exhibit its optoelectronic properties intrinsic uniformity in the molecular level is required. Thus, a monomer of ethyl methacrylate with pendant carbazole group was synthesized and polymerized via Reversible Addition -Fragmentation Chain Transfer (RAFT) to produce polymers with controlled molecular weight distribution and narrow polydispersity index (PDI). This method of polymerization was compared with that of free radical polymerization by gel permeation chromatography (GPC). The RAFT's polymerization kinetics was observed to follow a plot of number average molecular weight $(\mathrm{Mn})$ versus $\%$ conversion, characteristic of living polymerization. It was also shown to possess polymer chain extension capability. The structure of the monomer and the polymers were characterized by Fourier-Transform Infrared Spectroscopy (FT-IR) and Nuclear Magnetic Resonance (NMR).
\end{abstract}

Keywords: carbazole; poly[2-(9H-carbazol-9-yl)ethyl methacrylate]; reversible addition fragmentation chain-transfer (RAFT) polymerization; living polymerization; polymerization kinetics; polydispersity index $(P D I)$

\section{INTRODUCTION}

Fabrication of organic and hybrid optoelectronic devices needed thin films that would act as photoconductors or carriers of electron and holes. These thin films should have high charge carrier mobilities, hole transporting capability, high thermal and photochemical stability and electroluminescent properties. To provide these electro-optical and photovoltaic properties, scientists have turned to the use of $\pi$ conjugated polymers (Zhao et al., 2007). $\Pi$-conjugated organic polymers as photovoltaic components provide a very efficient matrix for current carrier transport. Other types of organic polymers have been used as auxiliary materials to support the high performance of conjugated polymers in actual devices (Gilot, 2010) These organic semiconductors are understood as onedimensional conductors with electrons (or holes) mainly travelling through conjugated chains or stacks of $\pi$-conjugated molecules (Taranekar et al., 2007). One type of these $\pi$ conjugated polymer materials is based on carbazole compound. 
Polymers based on carbazole units are interesting because of their electro-optical properties. Different substituents can be easily introduced into the carbazole ring and the carbazolyl groups can easily form relatively stable radical cations (holes).. These properties of carbazole-based compounds have attracted interest that made poly $(N$-vinylcarbazole $)$ PVK the first and the most widely studied organic polymeric photoconductor (Grazulevicius et al., 2003). This intense attention on carbazolecontaining polymers started with the discovery of photoconductivity in PVK by Hoegl (1965). The high levels of photoconductivity exhibited by PVK sensitized with suitable electron acceptors has become useful in practical applications like electrophotography. Furthermore, the growing interest in carbazole-containing polymers was brought mostly with the discovery of polymeric light emitting diodes and organic photorefractive materials. Also, they have been studied as components of photovoltaic devices. Recently they have also been found to be good electrochemichal capacitors (Wang et al., 2017) and memristors (McFarlane et al., 2018).

From the structural point of view, the polymers containing carbazole as charge-transporting groups can be divided into two classes, 1) polymers and oligomers with carbazole as the pendant groups in the side chains and 2) those with isolated carbazole groups in the main chains. Such functional polymers containing charge-transporting groups have found wide applications in the field of organic electronics (Zhao et al., 2007).

One example of this kind of polymers is: poly(2( $N$-carbazolyl)ethyl methacrylate) which has been synthesized from its corresponding methacrylate monomer by free radical polymerization with azobis isobutyronitrile (AIBN) as its initiator (Oshima et al., 1985). Most of these polymers with pendant carbazole groups were synthesized by conventional radical polymerization and controlling their molecular weights (MWs) and their architectures are quite challenging. The intrinsic wide polydispersity and difficulty in purifying these polymers were the critical problems that affect the performance of photovoltaic, electroluminescent and light emitting devices. In order to control MWs, polydispersities, topologies, compositions, and functional groups to manifest unique photoelectronic properties, precise synthetic methodologies must be established (Yu et al., 1995).

Recent developments in controlled radical polymerizations enabled the synthesis of various functional polymers with controlled MW, narrow MW distribution, and well-defined architectures and functionalities by a facile approach (Zhao et al., 2007). The systems included atom transfer radical polymerization (ATRP), nitroxide mediated radical polymerization (NMP), and reversible addition-fragmentation chain transfer (RAFT) polymerization. $\mathrm{Lu}$ and co-workers (2005), synthesized novel well-defined polyfluorenebased light-emitting rod-coil block copolymers via ATRP process. However, the presence of metal catalyst residues in living polymerizations such as ATRP could impair device performance. Living radical polymerization and block copolymerization of vinyltriphenylamine (as hole conductor) and perylene bisimide acrylate (as electron conductor) monomers via NMP were described by Lindner and Thelakkat (2004). Furuta et al. (2004) reported the synthesis of a multifunctional polymer- containing electron- (ET) and hole-transporting (HT) moieties as well as emitter complexes using NMP. RAFT technique drew interest among all these controlled/ living radical polymerizations, since it had emerged as a very attractive method for producing pseudo living free radical polymerizations, providing for control of molecular weight and molecular weight distributions with polydispersity indices typically in the range of 1.03-1.25 (Perrier and Takolpuckdee, 2005). It is capable of controlling the homopolymerization of a great variety of monomers such as styrenes, acrylates, methacrylates, vinyl esters, and polar or water-soluble monomers such as acrylamides and acrylic acid. Furthermore, RAFT process had the advantage of being carried out in the same conditions as a classic free radical polymerization except that it included the presence of chain transfer agent (CTA) also referred to as a RAFT agent. CTAs have high transfer coefficients in free radical polymerization and confer living character of the polymerization. As a result, RAFT polymerizations had been carried out in bulk, aqueous solutions (Mitsukami et al., 2001), organic solutions, suspensions, emulsions, mini and micro emulsions, and ionic liquids and could be carried out at low temperatures. In addition to simple homopolymers, a large variety of macromolecular structures had been synthesized via RAFT including statistical, block, multiblock, gradient, and comb copolymers, telechelic copolymers, star, hyperbranched, and network (co)polymers (Lott, 2006; Tian et al., 2018).

In this paper it is our objective a) to synthesize the monomer, ethylmethacrylate with pendant carbazole group, 2-(9H-carbazol-9-yl)ethyl methacrylate, b) to polymerize this monomer all the way to poly[2(9H-carbazol-9-yl)ethyl methacrylate] by RAFT polymerization (compared with conventional free radical polymerization, c) to determine the polymer molecular weight distribution and polydispersity, d) 
to demonstrate the polymer's living character by chain extension and e) to investigate its polymerization kinetics. The properties of the synthesized polymers are characterized using Fourier-Transform Infrared Spectroscopy (FT-IR), proton and carbon nuclear magnetic resonance $\left({ }^{1} \mathrm{H} \&{ }^{13} \mathrm{C}-\mathrm{NMR}\right)$. Molecular weight (MW) distribution and polydispersity indices (PDI) of the polymers are determined using GPC. This polymer can be used in the development of organic photovoltaic devices (OPVs) such as hole transport layer in polymer organic light emitting diodes (OLEDs) and polymer solar cells (PSCs) with a great potential in reducing its price and its negative environmental impact as compared to Si-based solar cells. These PSCs are solution processable organic materials with a potential to be fabricated on large area and flexible substrates (Taranekar et al., 2007; Tria et al., 2011). This paper however is limited only to the preparation of the polymer by RAFT and a demonstration of its advantage in the preparation of polymers with uniform molecular weight distribution for possible use in photoelectronics.

\section{EXPERIMENTAL}

Materials. Reagents and Instrumentation. The carbazole derivative, 2-(9H-carbazol-9-yl)ethanol was purchased from Trademax Pharmaceuticals \& Chemicals Co., Ltd. The chain transfer agent (CTA), 4-cyanopentanoic acid dithiobenzoate (CPDB), the initiator azobis (isobutyronitrile) (AIBN), N,N'-dicyclohexylcarbodiimide (DCC), 4-(N,N-dimethylamino) and methacrylic acid, were all purchased from Sigma-Aldrich and were reagent grade materials ( $99 \%$ purity). The initiator AIBN was purified by dissolving and recrystallizing in absolute methanol. Methacrylic acid with 250 ppm MEHQ as inhibitor was purified by passing through a column with alternating layers of aluminum oxide (activated and inhibitor remover prior to use. Tetrahydrofuran (THF) was dried by adding enough freshly cut solid sodium metal with benzophenone as indicator and distilled at $75^{\circ} \mathrm{C}$. All the other reagents used for this study were AR grade.

Characterizations were performed using NMR, FTIR and UV-Vis spectroscopy. ${ }^{1} \mathrm{H}$ and ${ }^{13} \mathrm{C}$ NMR characterization of the synthesized monomers and polymers were performed on an Agilent Varian spectrometer at $500 \mathrm{MHz}$ in $\mathrm{CDCl}_{3}$ with tetramethylsilane (TMS) as an internal standard. Samples were prepared by dissolving monomers and polymers $(5-10 \mathrm{mg})$ in $600 \mu \mathrm{L}$ deuterated chloroform $\left(\mathrm{CDCl}_{3}\right)$ and placing in pre-dried NMR tubes at room temperature. FTIR spectra of the monomers pelletized in $\mathrm{KBr}$ were obtained using a Shimadzu IR Prestige-21 FTIR-8400s spectrophotometer. Number average $\left(M_{n}\right)$, weight, average molecular weight $\left(\mathrm{M}_{\mathrm{w}}\right)$ and polydispersity index (PDI) were determined by gel permeation chromatography (GPC) using a Shimadzu LC-20AD Prominence liquid chromatograph equipped with a Shimadzu RID-10A refractive index detector (RID). Determination of molecular weight of polymers was based on a calibration using polystyrene standards with MW ranging from 820 to $900,000 \mathrm{~g} / \mathrm{mol}$. Tetrahydrofuran was used as the eluent through a TSK-GEL G3000HHR column at a flow rate of 1.0 $\mathrm{mL} / \mathrm{min}$.

Methods. The monomer and polymers were prepared using known literature procedures.

Synthesis of 2-(9H-Carbazol-9-yl)ethyl Methacrylate (CzEMA). To a $100 \mathrm{~mL}$ three-necked round bottom flask with $15 \mathrm{~mL}$ dry dichloromethane (DCM), $2.0 \mathrm{~g}$ (9.37 mmol, $9.37 \mathrm{meq})$ of 2-(9H-carbazol9-yl)ethanol, $0.936 \mathrm{~mL}$ methacrylic acid (11.0 $\mathrm{mmol}, 11.0 \mathrm{meq})$ and $173.5 \mathrm{mg}$ of $4-(N, N-$ dimethylamino)pyridine (1.406 mmol, $1.406 \mathrm{meq})$ were added. A $25 \mathrm{~mL}$ dropping funnel was fixed on the flask and a solution of $2.735 \mathrm{~g}$ of $N, N^{2}$ dicyclohexylcarbodiimide $(13.12 \mathrm{mmol}, 13.12$ $\mathrm{meq}$ ) in $5 \mathrm{~mL}$ of dry DCM was added. The reaction mixture was kept under nitrogen and was cooled for 30 minutes using an ice bath before adding the DCC solution in a dropwise manner $(5 \mathrm{~min})$. The ice bath was removed after complete addition of DCC and stirred at room temperature for 24 hours. The white byproduct, N,N-dicyclohexylurea, was removed by vacuum filtration. The mixture was washed with water and brine and then dried over $\mathrm{Na}_{2} \mathrm{SO}_{4}$. The solvent was removed by rotary evaporation and the product was recrystallized with ethanol. 2-(9H- carbazol-9-yl) ethyl methacrylate (CzEMA) was obtained as a white crystalline solid in $89 \%$ yield. ${ }^{1} \mathrm{H}$ NMR $\left(500 \mathrm{MHz}, \mathrm{CDCl}_{3}, \delta\right): 8.09$ $(\mathrm{d}, J=7.8 \mathrm{~Hz}, 2 \mathrm{H}), 7.57-7.35(\mathrm{~m}, 4 \mathrm{H}), 7.33-$ $7.14(\mathrm{~m}, 2 \mathrm{H}), 5.92(\mathrm{~s}, 1 \mathrm{H}), 5.46(\mathrm{~s}, 1 \mathrm{H}), 4.59(\mathrm{t}, J=$ $5.7 \mathrm{~Hz}, 2 \mathrm{H}), 4.52(\mathrm{t}, J=5.7 \mathrm{~Hz}, 2 \mathrm{H}), 1.79(\mathrm{~s}, 3 \mathrm{H})$; ${ }^{13} \mathrm{C}$ NMR (126 MHz, $\left.\mathrm{CDCl}_{3} \delta\right): 167.27,140.18$, $126.40,125.79,123.06,120.41,119.33,108.55$, 62.50, 41.64, 18.24. FT-IR (KBr) cm $\mathrm{cm}^{-1}$ 3048, 2976, 2922, 1718, 1628, 1597, 1485, 1456, 1317, 1170, 745,721 .

RAFT Polymerization of CzEMA. In a $25 \mathrm{~mL}$ Schlenk flask, 2-(9H-Carbazol-9-yl)ethyl methacrylate (1.396 g, $5 \mathrm{mmol}, 5 \mathrm{meq})$, CPDB (14 mg, $0.05 \mathrm{mmol}, 0.05$ meq), AIBN (4.105 mg, $0.025 \mathrm{mmol}, 0.050 \mathrm{meq})$ and $5 \mathrm{~mL}$ of dry THF ([M]:[CPDB]:[I] :100:1:0.2) were loaded together with a magnetic spinbar. Two solutions of the same concentration (1M) above were actually prepared. One solution (1M) was used solely for one RAFT polymerization experiment (see Table 1). From the other solution (1M) only 1.3 
$\mathrm{ml}(1 \mathrm{M})$ were taken. The $1.5 \mathrm{ml}(1 \mathrm{M})$ sample was diluted to $5 \mathrm{ml}$ with THF and used also for the RAFT polymerization as shown in Table 1 , and the rest of the solution for other experiments. For each sample, three freeze-pump-thaw cycles were performed to thoroughly deoxygenate the mixture and backfilled with nitrogen. It was then placed in a temperature regulated oil bath preheated at $60 \pm 1{ }^{\circ} \mathrm{C}$ for 20 hours. After 20 hours, polymerization was quenched by submerging the Schlenk tube in an ice bath and the septum was removed to expose the mixture to oxygen and stop the polymerization. To purify the polymer, it was precipitated out by adding the mixture while stirring to a 5 fold excess of methanol, collected by filtration and dried under vacuum at $40{ }^{\circ} \mathrm{C}$. The poly(CzEMA) was obtained in $91 \%$ yield as a pink powder (due probably to the pink CPDB). ${ }^{1} \mathrm{H}$ NMR (400 MHz CDCl 3 ( $\delta$ ppm): $7.93(\mathrm{~d}, 2 \mathrm{H}), 7.25-7.09$ (b, 6H), 4.18-3.98 (b, 4H), 1.6-1.39 (b, 2H), 0.14$0.19(\mathrm{~b}, 3 \mathrm{H})$ and other faint peaks due to the still attached CPDB at 8.2, 7.5, 1.8, and 0.9 FTIR (KBr), $\mathrm{cm}^{-1}: 3048,2953-2951,1718,1590-1622,1470-$ $1525,1217,1190,1160-1180,754$.

Free Radical Polymerization of CzEMA in the absence of 4-Cyanopentanoic acid dithiobenzoate (CPDB). The free radical polymerization was carried out in a similar way described above but in the absence of CPDB. CzEMA (1.396 g, $5 \mathrm{mmol}, 5 \mathrm{meq})$, AIBN (8.21 mg, $0.05 \mathrm{mmol}, 0.10 \mathrm{meq})$, were dissolved in dry THF $(0.5 \mathrm{~mL})$. For the experiment shown on Table 1 only two $1 \mathrm{ml}$ solutions were used, the rest were used in other experiments. Each solution were diluted to $5 \mathrm{~mL}$ THF and each were placed in a dry Schlenk tube, and then were deoxygenated by three freeze-pump-thaw cycles, and backfilled with nitrogen, and placed in an oil bath preheated to 60 ${ }^{\circ} \mathrm{C}$ for 40 hours. The resulting white product which is the poly (CzEMA) was obtained in $89 \%$ yield $(0.095$ g). $1 \mathrm{H}$ NMR (400 MHz, $\left.\mathrm{CDCl}_{3}, \delta \mathrm{ppm}\right): 7.92(\mathrm{~d}$, $2 \mathrm{H}), 7.24(\mathrm{~b}, 6 \mathrm{H}), 4.07(\mathrm{~b}, 4 \mathrm{H}), 1.26(\mathrm{~b}, 2 \mathrm{H}), 0.15$ (b, 3H). FTIR (KBr) cm $\mathrm{cm}^{-1}: 3047,2943,1728,1628$, $1597,1485,1456,1153,1020,748,723$.

Kinetic Experiment. In five separate $25 \mathrm{~mL}$ Schlenk flask, the following reagents were loaded and mixed for each flask together with a magnetic spinbar. The reagents, 2-(9H-Carbazol-9-yl)ethyl methacrylate (1.396 g, 5 mmol, $5 \mathrm{meq}$ ), CPDB (14 mg, 0.05 mmol, $0.05 \mathrm{meq})$ AIBN ( $4.105 \mathrm{mg}, 0.025 \mathrm{mmol}$, $0.050 \mathrm{meq})$ and $5 \mathrm{~mL}$ of dry THF ([M]:[CPDB]:[I] $: 100: 1: 0.2)$ were loaded together with a magnetic spinbar. The flasks were labelled: 5h, 10h, 15h, $20 \mathrm{~h}$ and $25 \mathrm{~h}$ denoting the number of hours that it will be heated. Three freeze-pump-thaw cycles were performed on each flask to thoroughly deoxygenate the mixture and back-filled with nitrogen. The flasks were placed in a regulated oil bath preheated at $60 \pm 1{ }^{\circ} \mathrm{C}$ for $5,10,15,20$ and 25 hours based on the label of the flasks. For the 5h-labeled flask, polymerization was quenched after 5 hours by submerging the Schlenk tube in an ice bath and the septum, removed to expose the mixture to oxygen and stop the polymerization. The liquid polymer was covered and kept in the refrigerator. The same quenching procedure was applied to the remaining flasks to stop polymerization after the specified number of hours in the flask.

Calculation of percent conversion through NMR peaks. The crude liquid polymer from the kinetic investigation experiment was subjected to NMR spectroscopy to calculate the percent conversion of the polymer. This was done by noting the integration values of the monomer methyl proton peaks (vinylic methyl protons) at $1.79 \mathrm{ppm}$ and the resulting polymer proton peaks (simple alkyl methyl protons) at $0.0-0.5 \mathrm{ppm}$ of the product. From these two values, the $\%$ conversion was calculated.

\section{RESULTS AND DISCUSSION}

The monomer 2-(9H-Carbazol-9-yl)ethylmethacrylate was first synthesized before it could be polymerized by RAFT and free radical polymerization. This was then followed by characterizations, demonstration of chain extension polymerization and then kinetic investigation.

Synthesis of Monomer. The procedure for the synthesis of the monomer was taken from the work of Taranekar et al. (2007) and Pokladko et al. (2008). The experiment produced a fairly good yield (89\%) of a white crystalline product. See Scheme 1.

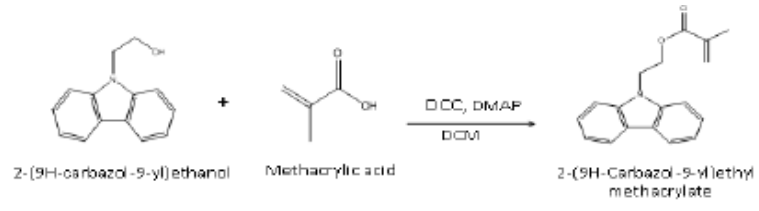

Scheme 1. Synthesis of 2-(9H-Carbazol-9-yl)ethyl methacrylate (CzEMA) by Esterification of Methacrylic Acid with 2-(9H-Carbazol-9-yl)ethanol.

\section{Polymerization of 2-(9H-carbazol-9-yl)ethyl methacrylate (CzEMA). Polymerization of} 2-(9H-carbazol-9-yl)ethyl methacrylate (CzEMA) was carried out in THF at $60{ }^{\circ} \mathrm{C}$ using $\mathrm{CPDB}$ and AIBN as initiator (Scheme 2).

The chain transfer agent 4-cyanopentanoic acid dithiobenzoate $(\mathrm{CPDB})$ was recommended as the best from a list of compatible CTAs for RAFT polymerization of methacrylate monomers (Keddie, 2014). Table 1 shows a summary of the experimental conditions and results of the syntheses. 


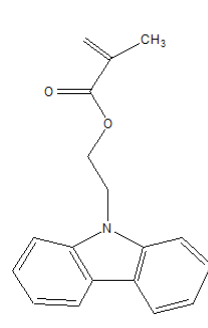

CZEMA

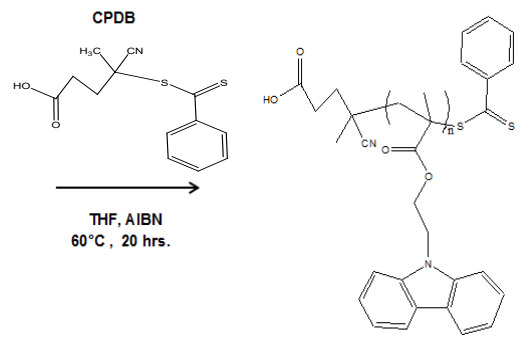

$\operatorname{Poly}(\mathrm{CzEMA}) \cdot \mathrm{CPDB}$
Scheme 2. Synthesis of poly $(C z E M A) \cdot C P D B$ by RAFT Polymerization of 2-(9H-Carbazol-9-yl)ethyl Methacrylate (CzEMA).

CzEMA was RAFT-polymerized at different initial concentrations, $[\mathrm{CzEMA}] 0=0.3$ and $1 \mathrm{M}$. The results (Table 1) showed that the process could be performed at 0.3 and $1 \mathrm{M} \mathrm{CzEMA}$ concentration conditions without significantly affecting the polydispersity index. This showed that monomer concentrations have less influence on the PDI of RAFT polymerizations (at a concentration used for photovoltaic film fabrication). As can be observed, polydispersity indices (PDI) of the resulting polymers synthesized via RAFT were narrow $(<1.30)$ as expected for controlled living polymerization. GPC measurements showed that the RAFT polymerization process was well controlled in terms of molecular weight and molecular weight distributions with narrow PDI. A control experiment was also conducted for comparison of the polymerization results obtained via RAFT and conventional free radical polymerization of CzEMA (Table 1, Figure 1). The polymerization of CzEMA in the absence of CPDB yielded a white homopolymer with a broad MW distribution; $M_{n}=6,130 \mathrm{~g} / \mathrm{mol}, M_{w} / M_{n}=2.67$. In contrast, the MW distribution of the polyCzEMA obtained via RAFT polymerization was narrow $\left(M_{\mathrm{w}} / \mathrm{M}_{\mathrm{n}}=1.17\right)$, with a number average $\mathrm{MW}$ of $M_{n}=5,652 \mathrm{~g} / \mathrm{mol}$, as determined by GPC (Figure
1).The significant difference in the MWs and PDI of the polymers obtained in the presence and absence of CPDB shows the efficiency of the RAFT reaction in achieving controlled polymerization.
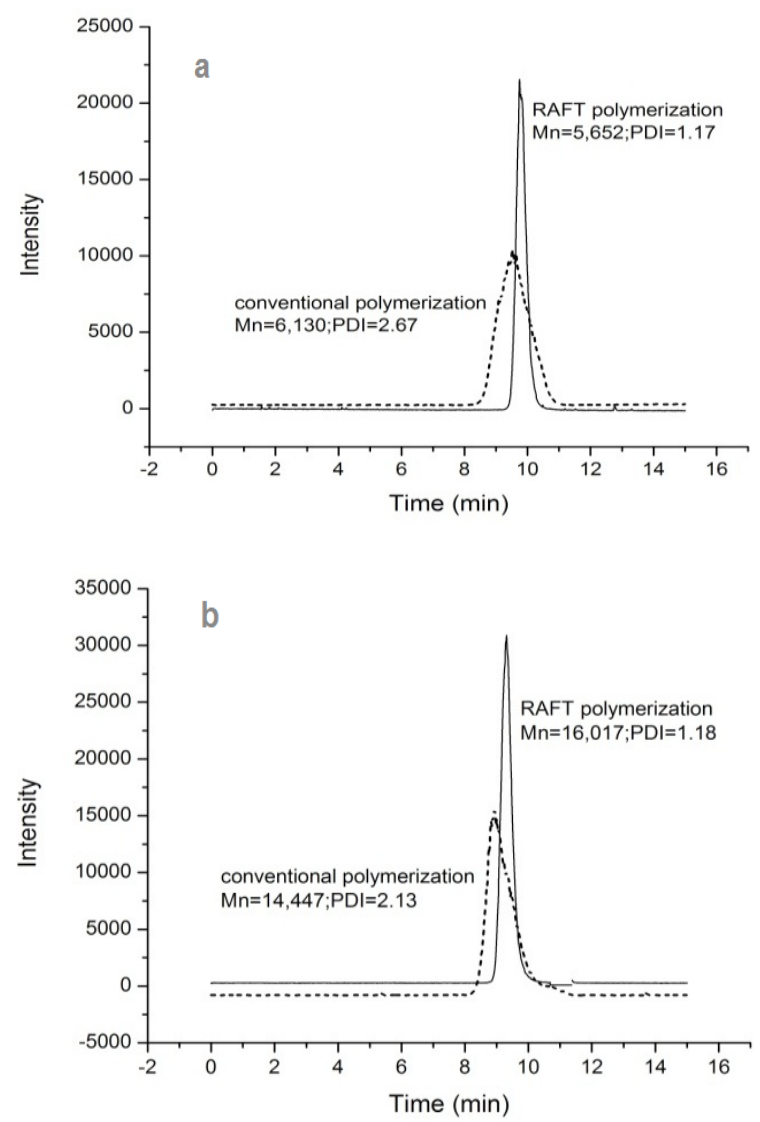

Figure 1. GPC of poly(CzEMA) via RAFT and Free Radical Polymerization Showing Consistent PDI Differences at Different Conditions; (a) in the presence of $C P D B$ (solid line, $M_{n}=5,652 ; P D I=1.17$ ) and in the absence of $C P D B$ (dashed line, $\left.M_{n}=6,130 ; P D I=2.67\right)$ (b) in the presence of $C P D B$ (solid line, $M_{n}=16,017$; $P D I=1.18$ ) and in the absence of $C P D B$ (dashed line, $\left.M_{n}=14,447 ; P D I=2.13\right)$ at $60^{\circ} \mathrm{C}$ in $T H F$.

Table 1. MolecularWeight and Polydispersity Indices (PDI) of polyCzEMA Prepared via RAFT(presence of CPDB) and Free Radical Polymerization (absence of CPDB).

\begin{tabular}{|c|c|c|c|c|c|}
\hline Concentration (M) & $\begin{array}{c}\mathrm{CPDB}^{\mathrm{a}} \\
(\mathrm{M})\end{array}$ & $\begin{array}{c}\operatorname{Time}^{\mathrm{b}} \\
\text { (h) }\end{array}$ & $\begin{array}{c}\text { Yield } \\
(\%)\end{array}$ & GPC $(\mathrm{MW})^{\mathrm{c}}$ & $\operatorname{PDI}\left(M_{w} / M_{n}\right)$ \\
\hline CzEMA $_{\text {RAFT }}(0.3) 1.5$ mmoles & 0.01 & 20 & 75 & $5,652 \pm 591$ & $1.17 \pm 0.04$ \\
\hline $\mathrm{CzEMA}_{\mathrm{RAFT}}$ (1) 5 mmoles & 0.01 & 20 & 91 & $16,017 \pm 995$ & $1.18 \pm 0.01$ \\
\hline $\begin{array}{l}\text { CzEMA }(0.1) \\
0.5 \text { mmole }\end{array}$ & 0 & 36 & 67 & $6,130 \pm 465$ & $2.67 \pm 0.10$ \\
\hline $\begin{array}{l}\text { CzEMA }(0.1) \\
0.5 \text { mmole }\end{array}$ & 0 & 40 & 89 & $14,447 \pm 2172$ & $2.13 \pm 0.32$ \\
\hline
\end{tabular}

Note: Concentration of AIBN initiator was $0.005 \mathrm{M}$ for all the above experiments

a. Concentration of chain transfer agent in molarity

b. Duration of RAFT polymerization in hours (determined from the time polymer with expected $\mathrm{M}_{\mathrm{n}}$ appeared as computed from equation (1).

c. MW as determined by GPC (with THF as eluent and calibrated with polystyrene standards) 
Poly(CzEMA) showed good solubilities in common organic solvents such as dichloromethane, chloroform and chlorobenzene. This high solubility in organic solvents could make this polymer potential candidate for practical applications such as in spin coating or inkjet-printing processes for high performance thin films in optoelectronic devices (Hshiao et al., 2013).

The ${ }^{1} \mathrm{H}$ NMR spectrum of the monomer compared with that of poly(CzEMA) produced by the RAFT and free radical polymerization are shown in Figures 2 to 4 . The ${ }^{1} \mathrm{H}$ NMR spectra of the monomer CzEMA provides the reference peaks for the ethylcarbazole pendant groups of the polymers such as the aromatic carbazole peaks at 8.09 (a), 7.57-7.5 (b) (c), 7.33-7.14 (d) and the ethyl peaks at 4.59 (f), 4.52 (e). The ethenyl and the methyl peaks shifted as the monomer underwent polymerization. The polymers' (from RAFT and free radical polymerization) spectra showed complex multiplet peaks in the aromatic region, $\delta=8.09 \mathrm{ppm}, \delta=$ 7.57-7.35 ppm and $\delta=7.33-7.14 \mathrm{ppm}$, assigned to the positions of the carbazole aromatic protons. The ethyl side chains $\left(-\mathrm{CH}_{2} \mathrm{CH}_{2}-\right)$ were detected at $\delta=4.59 \mathrm{ppm}$ and $\delta=4.52 \mathrm{ppm}$. The monomer peaks of the ethylene group on the methacrylate at $\delta=5.48$ and $\delta=5.92 \mathrm{ppm}$ shifted to the methylene peaks at $\delta=1.0-1.5 \mathrm{ppm}$ for the free radical polymer and the RAFT polymer, while the methyl group of the monomer at $\delta=1.79 \mathrm{ppm}$ shifted to peaks at $0.1 \mathrm{ppm}$ in the polymer because of a change in the neighboring structure (vinylic to alkyl). There are however additional peaks (much less intense) in the RAFT's polymer due to the CTA since the CPDB was still attached to it. These were assigned by numbers in Figure 4.

Other unassigned peaks in Figure 3 for the free radical polymerization could be due to the isobutyronitrile fragments from AIBN and other possible bonding interactions such as the tail to tail and head to head in addition to the more favored head to tail orientation. The IR spectra (Figure 5) supplement these data.

The IR spectra of the reagent 9H-Cbz-OH had a characteristic $-\mathrm{OH}$ peak at $3300 \mathrm{~cm}^{-1}$. This $\mathrm{OH}$ peak disappeared in the spectra of the monomer CzEMA and a carbonyl band due to the methacrylate appeared at $1718 \mathrm{~cm}^{-1}$, showing the resulting esterification of $9 \mathrm{H}-\mathrm{Cbz}-\mathrm{OH}$ to methacrylic acid. This band centered at $1718 \mathrm{~cm}^{-1}$ could be found in both the monomer CzEMA , and the polymer poly(CzEMA). The presence of peaks ranging from $730-750 \mathrm{~cm}^{-1}$ indicates the out of plane ring bending modes of 1,2 disubstituted benzenes of the carbazole groups in the three compounds. Other peaks such as the $\mathrm{C}-\mathrm{H}$

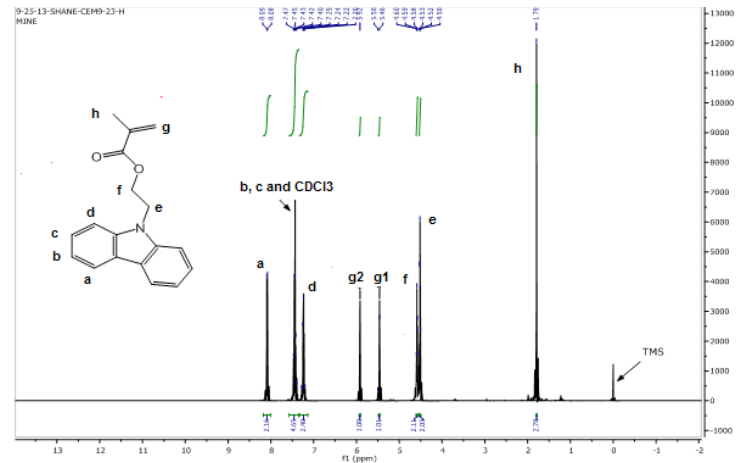

Figure 2. ${ }^{1} H N M R$ of the Monomer CzEMA.

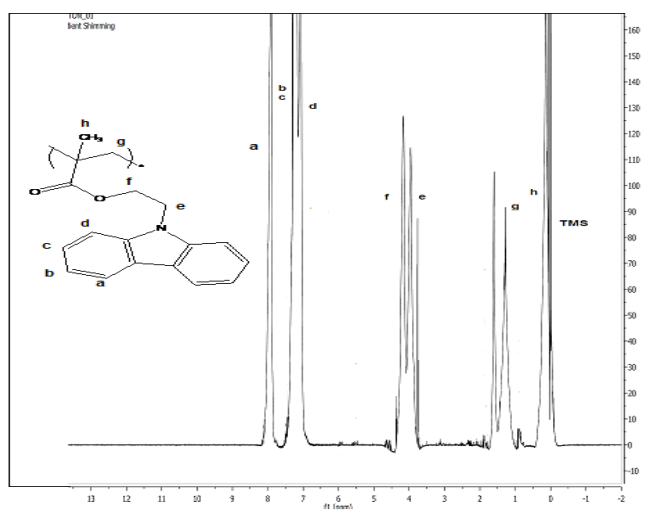

Figure 3. ${ }^{1} \mathrm{HNMR}$ of poly (CzEMA) from Free Radical Polymerization.

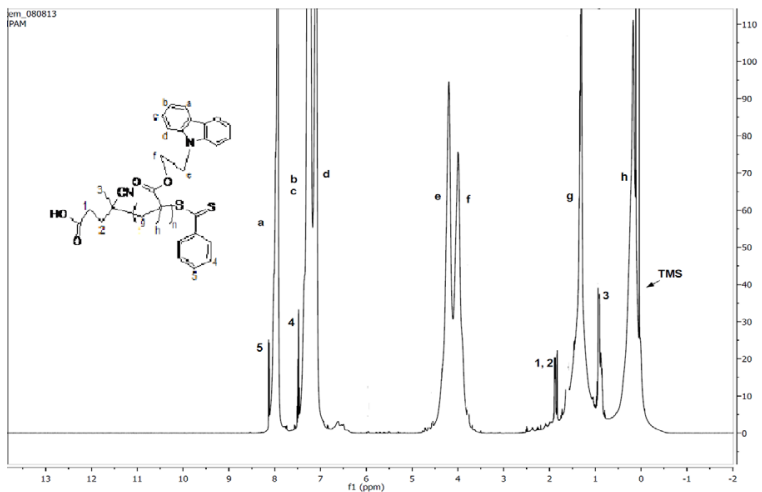

Figure 4. ${ }^{1} H N M R$ of $\operatorname{Poly}(C z E M A)$ from RAFT Polymerization.

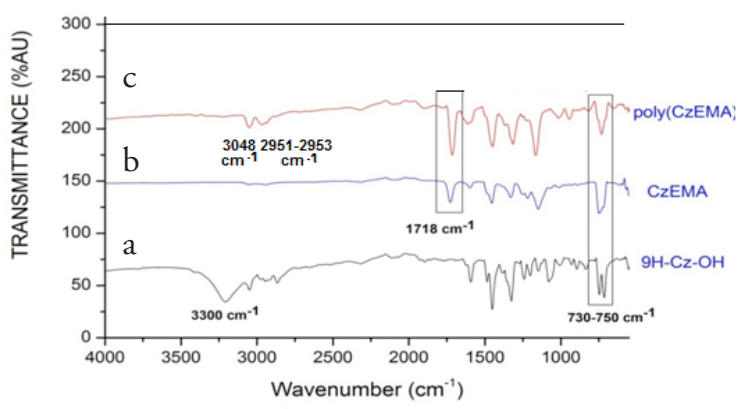

Figure 5. FTIR spectra of (a) 9H-Carbazole-OH, (b) the Monomer with Carbazole Pendants Attached to Ethyl Methacrylate (CzEMA) and (c) poly(Carbazole ethyl methacrylate), poly(CzEMA). 
stretching vibration of the alkyl chains, 2953 to 2951 $\mathrm{cm}^{-1}$, aromatic C-H stretch at $3048 \mathrm{~cm}^{-1}, 1590-1622$ $\mathrm{cm}^{-1}$ and $1470-1525 \mathrm{~cm}^{-1}$ aromatic carbazole $(\mathrm{C}=\mathrm{C})$ ring stretch , 1314-1326 $\mathrm{cm}^{-1}(\mathrm{C}-\mathrm{N})$ ring stretch, $1168-1180 \mathrm{~cm}^{-1} \mathrm{C}-\mathrm{O}$ stretch, were all observed in the spectra of the monomer and the polymer.

Chain-Extension Polymerization. All polymer chains generated during the RAFT process carry a thiocarbonylthio end group from the chain transfer agent (CTA) in this case, CPDB, used in the polymerization (Scheme 3). These polymer chains act as a so-called macro-RAFT agents which can be further extended.

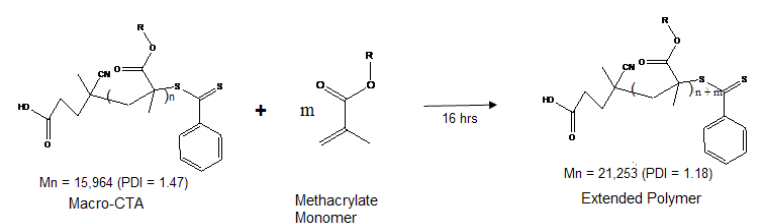

Scheme 3. Structure of Macro-chain Transfer Agent (macro-CTA) Containing the Dithio-end Reacting with Another Methacrylate Monomer in RAFT Polymerization.

As with other living radical polymerization techniques, RAFT allows chain extension of a polymer of one monomer with a second type of polymer to yield a block copolymer. The macro-RAFT agent takes on a similar role as the low molecularweight RAFT agent during homopolymerization. In order to verify that the macro-CTA used in this polymerization has still the characteristic of a living polymer, a chain-extension polymerization was done. It was observed that (after 20 hours of polymerization, almost all of the monomers have been consumed and approximately $M_{n}=15,964$ $\mathrm{g} / \mathrm{mol}$ was produced) when polymerization was resumed for another 16 hours, the polymer still increased its molecular weight by about $M_{n}=6,000$ $\mathrm{g} / \mathrm{mol}$ or 23 more carbazole units (Figure 6). Thus, this showed that the synthesized polymer could serve as a living macro-RAFT agent able to polymerize with the other monomers in the medium.

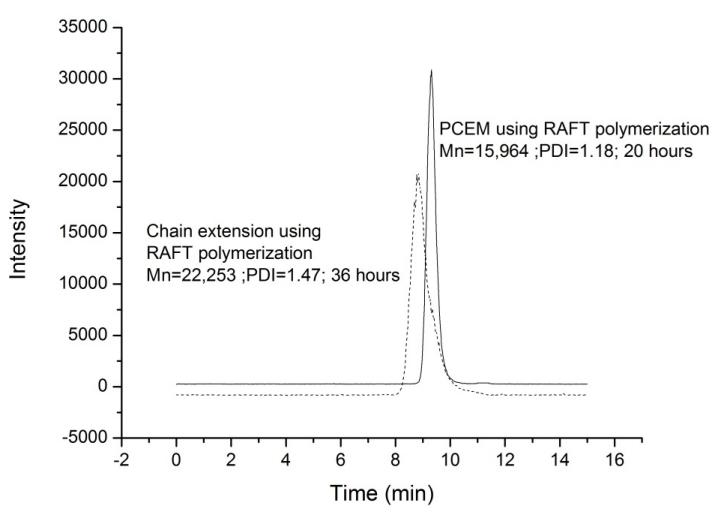

Figure 6. GPC Chromatograms of poly(CzEMA) Showing Controlled Living Characteristics (solid line, $M_{n}=15,964$; PDI =1.18) Polymerized for 20 hours and Chain Extended up to 36 hours (dashed line, $M_{n}=22,253 ; P D I=1.47$ ).

Kinetic Investigation. The controlled/living characteristics of RAFT polymerization were determined by performing kinetic investigations. The GPC-determined number-average molecular weights $\left(M_{n}\right.$, exp) were observed to be roughly comparable to the theoretical number-average molecular weights $\left(\mathrm{M}_{\mathrm{n}}\right.$, theor) calculated from equation 1 (Zhao et al., 2007);

$$
M_{n}(\text { theor })=\left[\frac{[\text { monomer }]_{0}}{[\mathrm{CTA}]_{0}} \times M_{\text {monomer }} \times p\right]+M_{\mathrm{CTA}}
$$

where $[\text { monomer }]_{0}$ and $[\mathrm{CTA}]_{0}$ are the initial concentration of monomer and CTA used, respectively. $\mathrm{M}_{\text {monomer }}$ is the molecular weight of the monomer, $p$ is the fractional conversion and $\mathrm{M}_{\mathrm{CTA}}$ is the molecular weight of CTA. Fractional conversion was calculated by NMR intergration data. Table 2 shows the data of the experiment. The linear increase in the molecular weight of the polymer $\left(M_{n}\right)$ versus \% conversion from the 5 th hour to the end of the experiment with low PDIs proved that this polymerization via RAFT is

Table 2. Progress of the Experimental ${ }^{a}$ and Theoretical Number-average Molecular Weights, \% Conversion and PDI of PolyCzMA with Time.

\begin{tabular}{|c|c|c|c|c|}
\hline $\begin{array}{c}\text { Time (hours) of CzEMA } \\
\text { Polymerization }\end{array}$ & $\begin{array}{c}\mathrm{Mn}^{\mathrm{b}} \\
\text { (Experimental) }\end{array}$ & $\%$ Conversion $^{\mathrm{c}}$ & $M_{n}$ (Theoretical) & $\operatorname{PDI}\left(\mathrm{M}_{\mathrm{w}} / \mathrm{M}_{\mathrm{n}}\right)$ \\
\hline $5 \mathrm{~h}$ & 1545 & 36 & 5305 & 1.05 \\
\hline $10 \mathrm{~h}$ & 3610 & 51 & 7399 & 1.09 \\
\hline $15 \mathrm{~h}$ & 6555 & 66 & 9494 & 1.17 \\
\hline $20 \mathrm{~h}$ & 7833 & 74 & 10611 & 1.28 \\
\hline $25 \mathrm{~h}$ & 8148 & 80 & 11449 & 1.19 \\
\hline
\end{tabular}

a The reaction was done in THF at $60{ }^{\circ} \mathrm{C}$; b. Determined by GPC; c. Determined from ${ }^{1} \mathrm{H}$ NMR spectra 
characteristically controlled. Similar kinetic data were obtained in the study of Zhao et al. (2007), on the polymerization of CzEMA showing the same increase of the number-average MW with low PDI $\left(\mathrm{M}_{\mathrm{w}} / \mathrm{M}_{\mathrm{n}}=1.15-1.30\right)$ versus percent conversion. A plot of $\mathrm{Mn}$, the molecular weight of the polymers against \% conversion is shown in Figure 7.

A discrepancy, however, between the theoretical and experimental number-average molecular weights $\left(M_{n}\right)$ can be observed from the results shown in the graph in Figure 7. The experimental curve showed that there was a lag in the increase of $\mathrm{M}_{\mathrm{n}}$ from $\%$ conversion = 0 to 36 . This lag shows that the values resulting from GPC which are the values of the $\mathrm{Mn}$ are much lower than expected as the NMR values for \% conversion are. This shows that the GPC is less sensitive than the NMR in this experiment. These differences may be attributed to the differences in hydrodynamic volume between the synthesized polyCzEMAs relative to the linear polystyrene standards used for GPC calibration (Zhao et al., 2007). Moreover, starting from the 5th hour, the similarity in the values of $M_{n}$ vs $\%$ conversion sloping curve $\left(\Delta \mathrm{M}_{\mathrm{n}} / \Delta(\%\right.$ conversion $\left.)=167.3\right)$ compared to the theoretical $\left(\Delta \mathrm{M}_{\mathrm{n}} / \Delta(\%\right.$ conversion $=142.8)$ is a normal characteristic of controlled $/$ living polymerization as differentiated from ordinary chain growth and step-growth polymerization whose sloping curves are both almost 0.0 at that range of the $\%$ conversion. A plot of the percent conversion as a function of PDI of the synthesized polymers is also shown in Figure 7, where the consistency of the low PDI in the range of the experiment using RAFT polymerization should be noted.

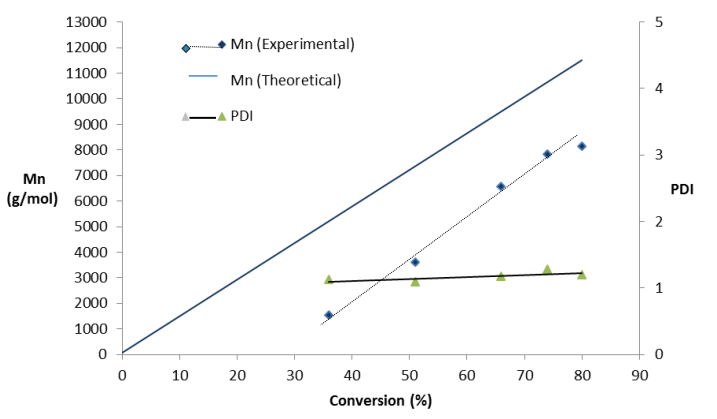

Figure 7. Molecular Weight and PDI versus Conversion Plots for RAFT Polymerization of CZEMA at $60^{\circ} \mathrm{C}$ in THF Monitored for 25 hours where Monomer Concentration=0.5 mol/L in the Ratio $[C z E M A] 0:[C P D B] 0:[A I B N] 0=50: 1: 0.2$.

Further demonstration of a well-controlled living polymerization with constant radical concentration is shown in a plot of $\ln (1 / 1$ - conversion) against time (h) of polymerization in Figure 8 and supported by data on Table 3. A first order plot obtained such as the figure shows, is a mark of living polymerization kinetics.
Table 3. Data for the First-order Plot of Polymerization Time vs Conversion

\begin{tabular}{cc}
\hline TIME $(\mathbf{h})$ & $\ln (\mathbf{1} / \mathbf{1 - C o n v})$ \\
\hline 0 & 0 \\
\hline 5 & 0.45 \\
\hline 10 & 0.71 \\
\hline 15 & 1.08 \\
\hline 20 & 1.35 \\
\hline 25 & 1.61 \\
\hline
\end{tabular}

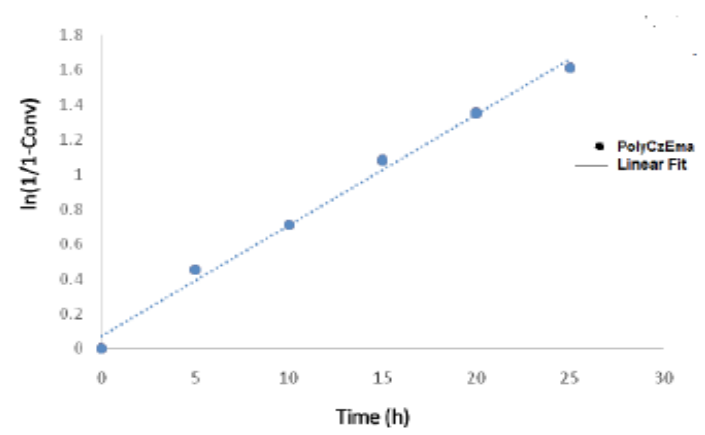

Figure 8. Plot of RAFT poly(CzEMA) conversion versus time.

\section{SUMMARY AND CONCLUSION}

A methacrylate monomer with pendant carbazole group has been successfully synthesized and polymerized to poly[2-(9H-carbazol-9-yl)ethyl methacrylate] by Reversible Addition Fragmentation Chain-Transfer (RAFT) and by conventional free radical polymerization. GPC of the polymers showed the advantage of RAFT over free radical polymerization with respect to molecular weight's distribution and polydispersity (PDI). Another feature of RAFT polymerization, its property to extend the polymer length as desired, a characteristic property of a living polymer, was also demonstrated. Its polymerization kinetics was investigated and found to follow a first order kinetics in a plot of $\ln (1 / 1$ conversion) versus time. It was found to follow also a linear sloping curve $\left(\Delta \mathrm{M}_{\mathrm{n}} / \Delta(\%\right.$ conversion $\left.)=167.3\right)$ when $M_{n}$ is plotted versus $\%$ conversion comparable to the theoretical slope $\left(\Delta \mathrm{M}_{\mathrm{n}} / \Delta(\%\right.$ conversion = $142.8)$ characteristic of a living polymerization. The synthesized polymers were characterized using Fourier-Transform Infrared Spectroscopy (FT-IR), proton and carbon nuclear magnetic resonance $\left({ }^{1} \mathrm{H} \&{ }^{13} \mathrm{C}-\mathrm{NMR}\right)$ and found consistent with their structures. The synthesized polymer would be of practical use in optoelectronics as its structure can be considered a potential "precursor polymer" if the carbazole pendant groups could be linked to form a continuous $\pi$ conjugation transforming them to 
conducting polymers (Taranekar et al., 2005) useful in optoelectronics. This process will be exploited in the next paper.

\section{ACKNOWLEDGEMENT}

The authors would like to thank the Philippine Council for Industry, Energy and Emerging Technology Research and Development (PCIEERD) of the Department of Science and Technology (DOST) of the Philippines for funding this research. Similarly, thanks are due to the Institute of Chemistry of the College of Science in the University of the Philippines at Diliman for the facilities of the laboratory as well as its personnel services.

\section{REFERENCES}

Furuta PT, Deng L, Garon S, Thompson ME and Fréchet JMJF. Platinum functionalized random copolymers for use in solution processible efficient near-white organic light emitting diodes. J Am Chem Soc. 2004;126:15388-15389.

Gilot J. Polymer Tandem Solar Cells [dissertation]. Technische Universiteit Eindhoven; 2010.

Grazulevicius JV, Strohriegl P, Pielichowski J, Pielichowski K. Carbazole-containing polymers: synthesis, properties and applications. Prog. Polym. Sci. 2003; 28(9): 1297-1353. doi:10.1016/S00796700(03)00036-4.

Hoegl H. On Photoelectric effects in Polymers and their Sensitization by Dopants. J. Phys. Chem. 1965;69(3):755 - 766.

Hsiao SH, Wang HM, Lin JW, Guo W, Kung YR, Leu CM, Lee TM. Synthesis and electrochromic properties of polyamides having pendent carbazole groups. Mater Chem Phys. 2013;141:665-673.

Keddie DJ. A guide to the synthesis of block copolymers using Reversible addition-fragmentation chain-transfer (RAFT) polymerization. Chem Soc Rev.2014;43:496-505.

Kettle J, Waters H, Horie M, Chang SW. Effect of hole transporting layers on the performance of PCPDTBT: PCBM organic solar cells. J Phys D Appl Phys. 2012;45(12):125102. doi:10.1088/0022$3727 / 45 / 12 / 125102$.

Lindner SM, and Thelakkat M. Nanostructure of $\mathrm{N}$-type organic semicon in a p-type matrix via selfassembly of block copolymers. Macromolecules. 2004;37(24):8832-8835.
Lim TH, Oh KW, Kim SH. Effect of self-assembly supramolecules on the electrical properties of polyaniline based hole transport layer. Synth Met. 2012;162(3-4):268-275. doi:10.1016/j. synthmet.2011.12.002.

Lott JR. Reversible Addition-Fragmentation ChainTransfer (RAFT) Polymerization in Grafting Polymer Chains from $\mathrm{TiO}_{2}$ Nanoparticles.; [dissertation]. [Rochester]: Rochester Institute of Technology. 2006(August).

Lu S, Liu TX, Ke L, Ma DG, Chua SJ, Huang W. Polyfluorene-based light-emitting rod-coil block copolymers. Macromolecules. 2005;38:8494-8502.

McFarlane TM, Zdyrki B, Bandera Y, Worley $\mathrm{D}$, Klep O, Curca M, Tonkin C, Foulger SH, Vilcacova J, Saha P, Pfleger J. Design rules for carbazole derivatized $n$-alkyl(methacrylic) polymeric memristor. J. Mater. Chem. C. 2018;6:2533 - 2545.

Mitsukami Y, Donovan MS, Lowe AB, McCormick CL. Water-soluble polymers. 81. Direct synthesis of hydrophilic styrenic-based homopolymers and block copolymers in aqueous solution via RAFT. Macromolecules. 2001;34(7):2248-2256. doi:10.1021/ma0018087.

Oshima R, Biswas M, Wada T, Uryu T. J Polym Sci, Part A: Polym Chem. 1985;23: 151.

Perrier S, Takolpuckdee PJ. Macromolecular design via reversible addition fragmentation chain transfer. Polym Sci Part A Polym Chem. 2005;43:53475393.

Pokladko M, Sanetra J, Gondek ., Bogdał D, Nizioł J, Kityk IV. Synthesis and polymerisation of novel methacrylates with carbazolyl and benzofuranyl pendant groups for photovoltaic applications. Mol Cryst Liq Cryst. 2008;484:335/[701] - 344/[710].

Taranekar P, Baba A, Fulghum TM, Advincula RC. Conjugated polymer network films from precursor polymers: Electrocopolymerization of a binary electroactive monomer composition. Macromolecules. 2005;38(9):3679-3687. doi:10.1021/ma050001h.

Taranekar P, Fulghum T, Patton D, PonnapatiR, Clyde G, Advincula RC. Investigating carbazole jacketed precursor dendrimers: sonochemical synthesis, characterization, and electrochemical crosslinking properties. J Am Chem Soc. 2007;129(41):1253712548. doi:10.1021/ja074007t.

Taranekar P, Fulghum T, Baba A, Patton D, 
Advincula RC. Quantitative electrochemical and electrochromic behavior of terthiophene and carbazole containing conjugated polymer network film precursors: EC-QCM and EC-SPR. Langmuir. 2007;23(2):908-917. doi:10.1021/la061820d.

Tian X, Ding J, Zhang B, Qiu F, Zhuang X. Recent advances in RAFT polymerization: Novel initiation mechanism and optoelectronic application. Polymers.2018;10:318 -

Tria MC, Liao K, Nigel A, Curran S, Advincula RC. Electrochemically crosslinked surface-grafted PVK polymer brushes as a hole transport layer for organic photovoltaics. J Mater Chem. 2011;21:1026110264.

Yu G, Gao J, Hummelen J. Polymer photovoltaic cells: enhanced efficiencies via a network of internal donor-acceptor heterojunctions. Science. 1995; 270:1789-1791.

Zhao P, Ling QD, Wang WZ, Ru J., Li SB, Huang W. Reversible addition-fragmentation chain transfer polymerization of methacrylates containing holeor electron-transporting groups. J. of Polym. Sci. Part A: Polymer Chemistry. 2007; 45(2): 242-252. doi:10.1002/pola.

Wang $\mathrm{H}$, Zheng Z, Liao Y, Li J, Weber J, Thomas A, Faul CFJ. Conjugated microporous polycarbazole network as precursor for nitrogenenriched microporous carbon for $\mathrm{CO}_{2}$ storage and electrochemical capacitor. Chem. Mater. 2017;29(11): 4885-4893. 